\title{
Comparative pelvic development of the axolotl (Ambystoma mexicanum) and the Australian lungfish (Neoceratodus forsteri): conservation and innovation across the fish-tetrapod transition
}

Catherine Anne Boisvert ${ }^{1,2^{*}}$, Jean MP Joss ${ }^{3}$ and Per E Ahlberg ${ }^{2}$

\begin{abstract}
Background: The fish-tetrapod transition was one of the major events in vertebrate evolution and was enabled by many morphological changes. Although the transformation of paired fish fins into tetrapod limbs has been a major topic of study in recent years, both from paleontological and comparative developmental perspectives, the interest has focused almost exclusively on the distal part of the appendage and in particular the origin of digits. Relatively little attention has been paid to the transformation of the pelvic girdle from a small unipartite structure to a large tripartite weight-bearing structure, allowing tetrapods to rely mostly on their hindlimbs for locomotion. In order to understand how the ischium and the ilium evolved and how the acetabulum was reoriented during this transition, growth series of the Australian lungfish Neoceratodus forsteri and the Mexican axolotl Ambystoma mexicanum were cleared and stained for cartilage and bone and immunostained for skeletal muscles. In order to understand the myological developmental data, hypotheses about the homologies of pelvic muscles in adults of Latimeria, Neoceratodus and Necturus were formulated based on descriptions from the literature of the coelacanth (Latimeria), the Australian Lungfish (Neoceratodus) and a salamander (Necturus).

Results: In the axolotl and the lungfish, the chondrification of the pelvic girdle starts at the acetabula and progresses anteriorly in the lungfish and anteriorly and posteriorly in the salamander. The ilium develops by extending dorsally to meet and connect to the sacral rib in the axolotl. Homologous muscles develop in the same order with the hypaxial musculature developing first, followed by the deep, then the superficial pelvic musculature.

Conclusions: Development of the pelvic endoskeleton and musculature is very similar in Neoceratodus and Ambystoma. If the acetabulum is seen as being a fixed landmark, the evolution of the ischium only required pubic pre-chondrogenic cells to migrate posteriorly. It is hypothesized that the iliac process or ridge present in most tetrapodomorph fish is the precursor to the tetrapod ilium and that its evolution mimicked its development in modern salamanders.
\end{abstract}

Keywords: Fish-tetrapod transition, Pelvic girdle, Heterochrony, Extant phylogenetic bracketing method, Evolutionary novelty, Muscle development

\footnotetext{
* Correspondence: Catherine.Boisvert@monash.edu

${ }^{1}$ Australian Regenerative Medicine Institute, Monash University, Wellington Road, Clayton, VIC 3800, Australia

2Subdepartment of Evolution and Development, Department of Organismal Biology, Evolutionary Biology Centre, Uppsala University, Norbyvägen 18A, Uppsala 752 36, Sweden

Full list of author information is available at the end of the article
} 


\section{Background}

Around 395 million years ago, the first tetrapods (fourlegged vertebrates) appeared, having evolved from lobefinned fish [1,2]. This fish-tetrapod transition was marked by many morphological transformations and ecological adaptations ranging from the evolution of fingers and toes [3-5] to new modes of respiration, hearing [6,7] and locomotion $[8,9]$. One of the major changes in locomotory habit is that of a shift from fish principally using their pectoral fins and lateral undulation to swim to tetrapods relying much more heavily on their hindlegs to swim and walk [10]. This shift from 'front-wheel drive' to 'back wheel drive' locomotion was enabled by the evolution of a large, weight-bearing pelvic girdle in tetrapods. In lobefinned fishes, the pelvic girdle is composed of a crescentric pubis often connected through cartilage at the midline but lacking an ilium to connect it and, consequently, the whole fin, to the vertebral column [11]. In tetrapods, not only is an ilium present and fused to the vertebral column through a sacral rib, but an ischium is also present posterior to the pubis. The pubis and ischium from both halves of the girdle are fused along their midlines and, hence, the girdle is weight-bearing [2]. Tetrapod legs are also oriented laterally compared to the posterior orientation of fish pelvic fins. This reflects the orientation of the acetabulum, which is located on the lateral face of the pelvis in tetrapods but at the posterior end of the pelvis in fish. The morphology of Paleozoic lobe-finned fish pelves is known from descriptions of Eusthenopteron [12] and other fish members of the tetrapod stem group $[13,14]$, as well as from stem dipnoans [15] and a porolepiform [11], and that of the earliest tetrapods by descriptions of Acanthostega [16] and Ichthyostega $[8,17]$. This provides a good picture of the general morphology on either side of the transition (Figure 1) but little information as to how the transformation occurred (Figure 1). In order to elucidate this, the pelvic girdle of the transitional fish Panderichthys was studied [18] but it is very fish-like and unfortunately does little to answer the following questions: Is the iliac process present in Eusthenopteron a precursor of the ilium of tetrapods? How did the ilium become connected to the sacral rib? How did the ischium evolve? And how did the acetabulum move during the transition?

In the absence of more informative fossils, we can use the Extant Phylogenetic Bracketing method [19] as a basis for framing hypotheses about how the transformation occurred. By comparing the development of the pelvic girdle in modern representatives of groups on either side of the

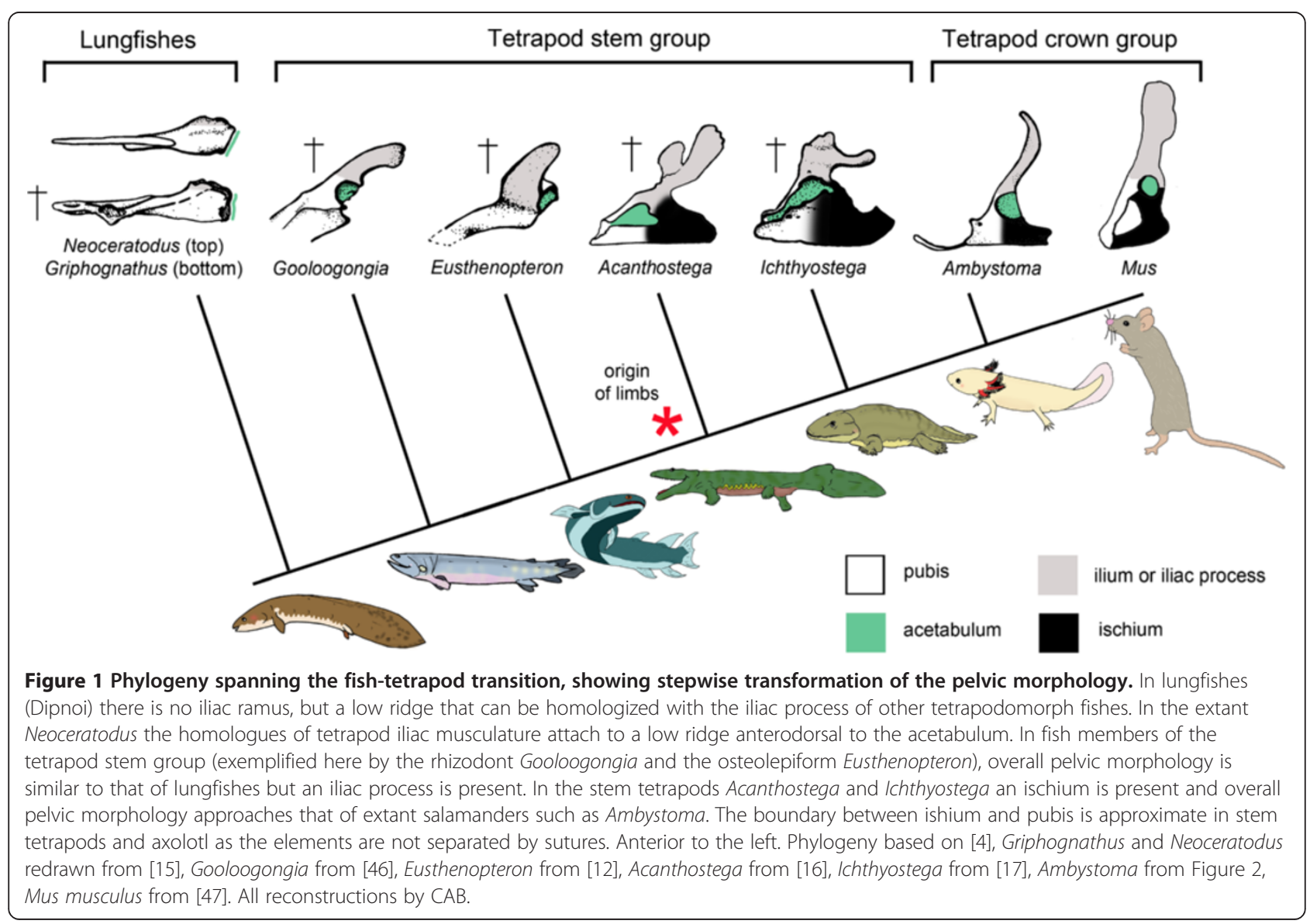


transition, we can determine which aspects are similar and, thus, likely to have been conserved from fish to tetrapod, and which appear to be tetrapod innovations. This approach not only illuminates the evolution of pelvic development, but provides clues for the interpretation of the adult morphologies of transitional fossils. Heterochronies in developmental sequences have proven useful in understanding evolutionary change and are, thus, of particular interest in this context $[20,21]$. The Australian lungfish (Neoceratodus forsteri) is a morphologically conservative member of the Dipnoi and is the only lobe-finned fish available for developmental studies. Fortunately, its pelvic girdle is very similar to that of Paleozoic dipnoans [15] and a good representation of the general lobe-finned fish pelvic shape (Figure 1). The Mexican axolotl (Ambystoma mexicanum) is a commonly used laboratory animal, which, like other salamanders, has a pelvic morphology very similar to that of early tetrapods. In both species, a cartilaginous anterior process (pubic process in Neoceratodus and ypsiloid cartilage in Ambystoma) is present. This process is absent, or arguably unpreserved, in both Devonian lungfish and in Devonian tetrapods, and so cannot be assumed to be homologous in the two groups. However, the pubis and acetabulum are uncontroversially homologous [22] and will be used here as landmarks for the developmental comparison.

The skeletal components of the pelvic girdle do not exist in isolation, but are intimately linked both developmentally and functionally to the muscles that attach there. In order to understand the transformation of the pelvis at the fish-tetrapod transition, it is thus important to consider not just the skeleton but also the musculature. Accordingly, we present here a comparison of muscular development in Neoceratodus and Ambystoma, as a complement to the skeletal study. Establishing a robust comparative framework for the muscular data is, however, a more complicated matter than for the skeletal data because the musculature of the pelvis and hind limb is far more complex than the skeleton and the mapping of homologies between taxa correspondingly more difficult. Establishing muscle homologies has been an important focus of comparative anatomy in the 19th and early 20th century [23-26] and its importance is now being put back into focus as a way of understanding and explaining evolutionary change $[27,28]$. Despite the adult pelvic musculature having been described for two of the living sarcopterygians, the coelacanth Latimeria chalumnae [29] and the Australian lungfish Neoceratodus forsteri [15], as well as for several salamanders $[23,24,30]$ and several studies having been published on hindlimb muscle homologies [25,28], no attempt has been made to establish detailed muscular homologies across the fish-tetrapod transition. We based our mapping of muscle homologies on close representatives of the taxa used in the developmental study. As a representative for the axoltol, we used the mudpuppy Necturus maculosus [31] because of its close phylogenetic position and similarities to Ambystoma mexicanum [32,33]. We present a detailed comparison of the three musculatures, developed from published descriptions, with a set of proposed homologies (Tables 1, 2, 3, 4, 5). The proposed homologies are based on the points of origin and insertion of the muscles as well as their function, following established principles for such comparisons $[25,27,28]$.

\section{Methods}

\section{Salamander and lungfish larvae}

Albino larvae of the Mexican axolotl (A. mexicanum) were purchased from the Ambystoma genetic stock center at the University of Kentucky, USA. They were fixed in paraformaldehyde overnight and stored in 100\% methanol. The youngest larvae of the series used in this article were staged using the extended table of development developed by Nye et al. [34]. Given the absence of an adequate development table, older larvae were staged according to total length (in $\mathrm{cm}$ ). Larvae of the Australian lungfish $(N$. forsteri) were raised in captivity from eggs collected in the lungfish spawning ponds at Macquarie University (protocols approved by the Macquarie University Animal Ethics Committee, approval \# 2003/001). The embryos were left to hatch and develop for approximately five months, being fed on brine shrimp and bloodworms (for older larvae). The youngest larvae used in this study were staged using the developmental table developed by Kemp [35]. Fish older than stage 55 (latest stage of the table) were staged according to pelvic fin length and were given a stage number corresponding to the same developmental progress as between stages 54 and 55 . The larvae were euthanized with Tricaine (MS-222) and fixed overnight in $4 \%$ paraformaldehyde with a $\mathrm{pH}$ of 7.4 .

\section{Alcian blue and Alizarin red staining No acid, Kimmel protocol}

Lungfish were cleared and stained using a protocol without acid developed by the Kimmel Laboratory (University of Oregon, USA) for zebrafish and modified by Catherine Anne Boisvert. The larvae were eviscerated and then washed in Tris/ $\mathrm{MgCl}_{2}$ before being transferred to Alcian stain solution $(0.02 \%$ alcian in $71 \% \mathrm{EtOH}$ and $25 \mathrm{mM} \mathrm{MgCl} 2$ in Tris $\mathrm{pH} 7.5$ aqueous solution) for a period ranging from three to seven days. The specimens were then rehydrated through a series of ethanol in 100 $\mathrm{mM}$ Tris $\mathrm{pH} 7.5$ and $25 \mathrm{mM} \mathrm{MgCl}_{2}$ for 30 minutes each, after which they were bleached in $3 \% \mathrm{H}_{2} \mathrm{O}_{2}$ and $0.5 \%$ $\mathrm{KOH}$ for 20 to 22 hours with a change of solution. 
Table 1 Comparison of adductor muscles in the coelacanth (Latimeria), Australian lungfish (Neoceratodus) and mudpuppy (Necturus)

\begin{tabular}{|c|c|c|c|c|c|}
\hline Latimeria chalumn & & Neoceratodus fors & teri & Necturus maculos & \\
\hline $\begin{array}{l}\text { Superficial adductor, } \\
\text { main bundle } \\
\text { "Abaisseur } \\
\text { superficiel, } \\
\text { faiseau principal » } \\
\text { (Ventral) }\end{array}$ & $\begin{array}{l}\text { O:posterior border } \\
\text { of the mesial hypophysis } \\
\text { I: fascia attaching to the base } \\
\text { of lepidotrichia }\end{array}$ & $\begin{array}{l}\text { Superficial } \\
\text { ventromesial } \\
\text { adductor } \\
\text { (Dorsal and } \\
\text { ventral) }\end{array}$ & $\begin{array}{l}\text { O: Median } \\
\text { posteroventral margin } \\
\text { of the pelvis and the } \\
\text { superficial ventromesial } \\
\text { adductor from } \\
\text { the other side (for the } \\
\text { mesialmost fibres). } \\
\text { I: Distal medial process } \\
\text { on the first axial element } \\
\text { and on radials }\end{array}$ & $\begin{array}{l}\text { Ischioflexorius } \\
\text { (Adductor) } \\
\text { (Ventral) }\end{array}$ & $\begin{array}{l}\text { O: caudal end of } \\
\text { the ischium } \\
\text { l: Fascia of the distal } \\
\text { end of the shank. }\end{array}$ \\
\hline $\begin{array}{l}\text { Deep } \\
\text { adductor } \\
\text { "Abaisseur } \\
\text { profond » } \\
\text { (Ventral) }\end{array}$ & $\begin{array}{l}\text { O: Middle of the pubis } \\
\text { and posterior part of } \\
\text { the pubic ramus. } \\
\text { l: through tendons onto the } \\
\text { fascia of the superficial } \\
\text { adductor, main bundle }\end{array}$ & $\begin{array}{l}\text { Superficial ventro- } \\
\text { lateral adductor } \\
\text { (Ventral) }\end{array}$ & $\begin{array}{l}\text { O: Median } \\
\text { posteroventral } \\
\text { margin of the pelvis } \\
\text { I: Distal medial } \\
\text { process on the } \\
\text { first axial element } \\
\text { and radials }\end{array}$ & $\begin{array}{l}\text { Puboischio-tibialis } \\
\text { (Adductor) } \\
\text { (Ventral) }\end{array}$ & $\begin{array}{l}\text { O: Ventral and } \\
\text { caudal part of the } \\
\text { pubis, most of } \\
\text { the ischium } \\
\text { I: Proximal end } \\
\text { of the } \\
\text { tibia }\end{array}$ \\
\hline $\begin{array}{l}\text { Pronators } \\
1+2+3 \\
\text { (Dorsal) }\end{array}$ & $\begin{array}{l}\text { O: very middle of } \\
\text { the pubis on dorsal } \\
\text { side } \\
\text { l: } 3 \text { first preaxial radials } \\
\text { and } 10 \text { first preaxial } \\
\text { lepidotrichia }\end{array}$ & $\begin{array}{l}\text { Deep ventral } \\
\text { adductor } \\
\text { depressor } \\
\text { (Dorsal) }\end{array}$ & $\begin{array}{l}\text { O: Posterodorsal and } \\
\text { posteroventral faces } \\
\text { of the pelvis } \\
\text { I: Base of first } \\
\text { fin element }\end{array}$ & $\begin{array}{l}\text { Ischiofemoralis } \\
\text { (Adductor) } \\
\text { (Ventral) }\end{array}$ & $\begin{array}{l}\text { O: Ischium } \\
\text { l:Proximal } \\
\text { end of the } \\
\text { femur }\end{array}$ \\
\hline $\begin{array}{l}\text { Fin adductor } \\
\text { "Adducteur } \\
\text { de la } \\
\text { nageoire» } \\
\text { (Dorsal) }\end{array}$ & $\begin{array}{l}\text { O :Arcuate ridge on } \\
\text { the dorsal side } \\
\text { I: Fascia of the 5th } \\
\text { pronator and base } \\
\text { of the 9th and 10th } \\
\text { lepidotrichia. }\end{array}$ & $\begin{array}{l}\text { Dorsomesial } \\
\text { adductor } \\
\text { levator } \\
\text { (dorsal) }\end{array}$ & $\begin{array}{l}\text { O: Arcuate ridge } \\
\text { (posterior dorsal part, } \\
\text { anterior to the } \\
\text { acetabulum) } \\
\text { l: Proximal and } \\
\text { subsequent fin } \\
\text { elements }\end{array}$ & & \\
\hline
\end{tabular}


Table 1 Comparison of adductor muscles in the coelacanth (Latimeria), Australian lungfish (Neoceratodus) and mudpuppy (Necturus) (Continued)

Latimeria chalumnae Neoceratodus forster Neoceratodus forste

Mesial adductor O: Muscles of fin

(Dorsal) elements from one side

I: Muscles of fin

elements from the

other side

Necturus maculosus

Puboischio-femoralis $\quad$ : ventral surface of externus (Adductor) the girdle/Pubis and Ventral) ischium

I: Proximal end of

the femur

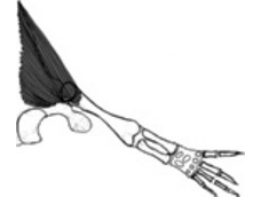


Table 2 Comparison of abductor muscles in the coelacanth (Latimeria), Australian lungfish (Neoceratodus) and mudpuppy (Necturus)

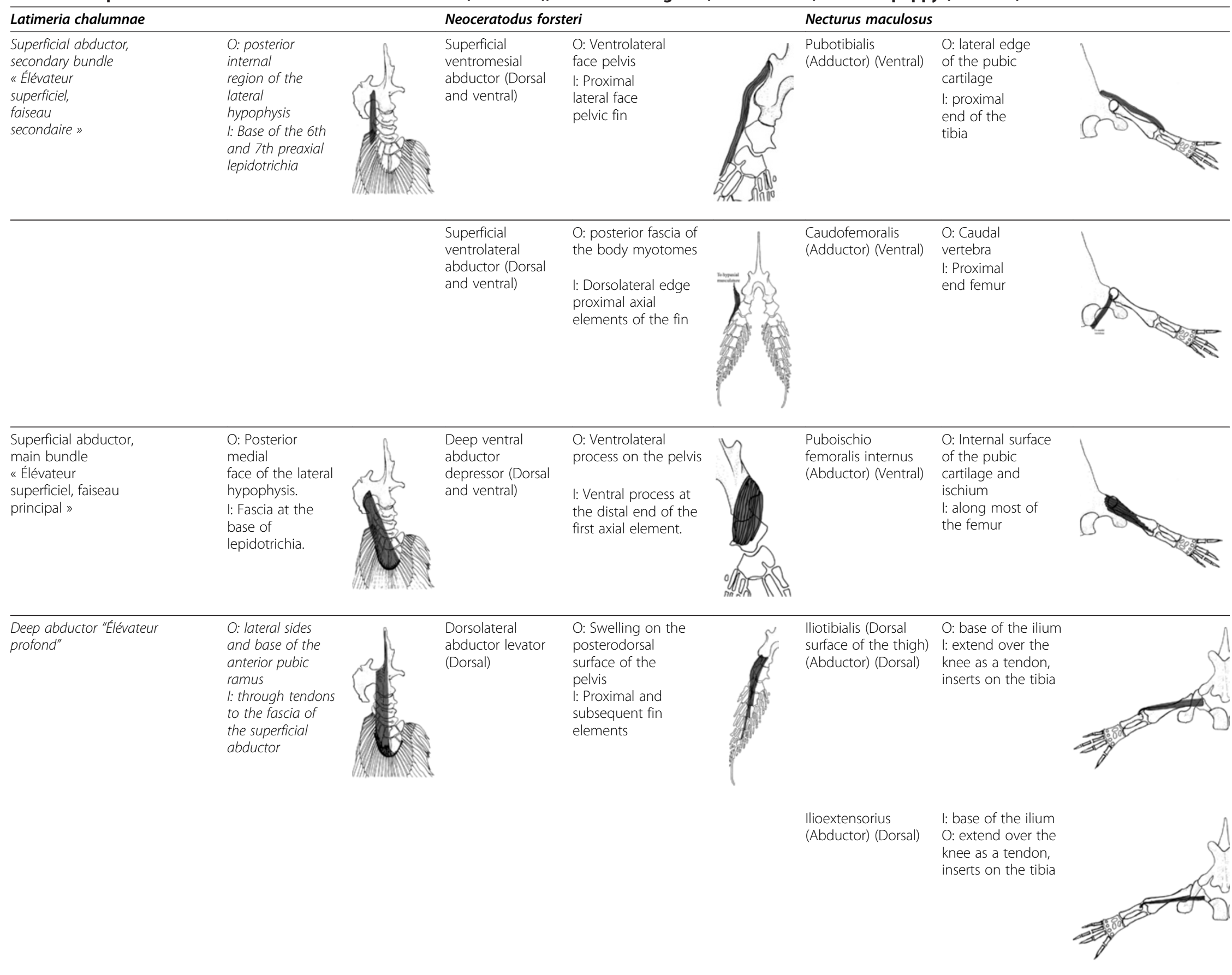


Table 2 Comparison of abductor muscles in the coelacanth (Latimeria), Australian lungfish (Neoceratodus) and mudpuppy (Necturus) (Continued)

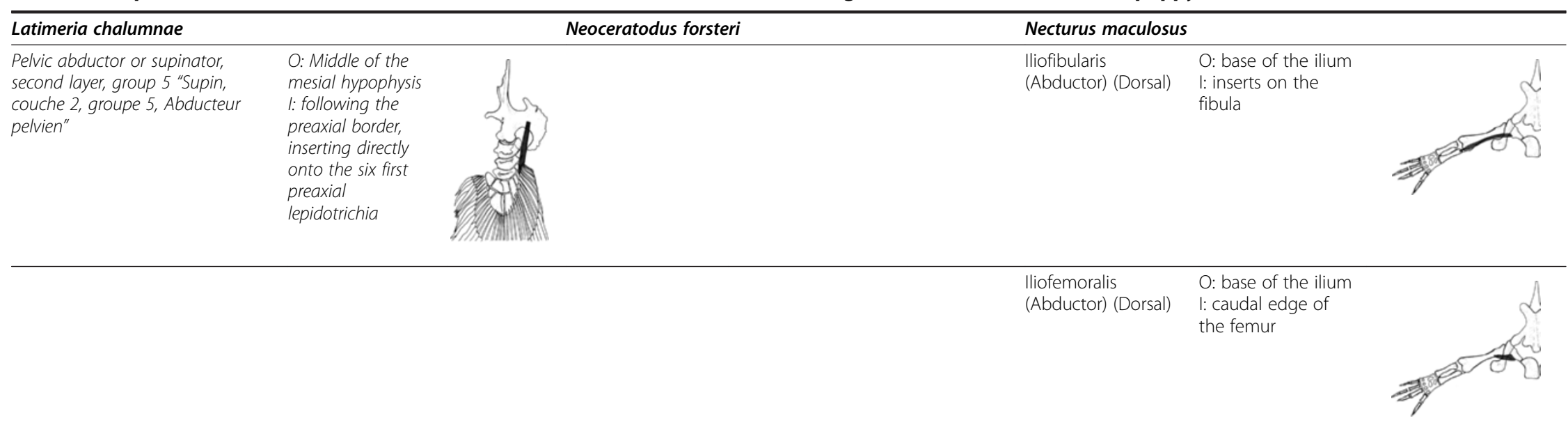


Table 3 Comparison of adductor/abductor muscles in the coelacanth (Latimeria), Australian lungfish (Neoceratodus) and mudpuppy (Necturus)

\begin{tabular}{lll}
\hline Latimeria chalumnae & Neoceratodus forsteri & Necturus maculosus \\
\hline Radial flexors $\mathrm{O}$ : fin elements \\
(Adductor and I: fin elements \\
abductor)
\end{tabular}

Muscles were digested away at room temperature in a solution of $1 \%$ pancreatin in $35 \%$ saturated sodium borate for 17 to 51 hours. The specimens were washed for one hour in $25 \%$ glycerol and $0.1 \% \mathrm{KOH}$ and then stained for bone in a solution of $0.02 \%$ Alizarin stain in $10 \%$ glycerol and $0.5 \% \mathrm{KOH}$ for two to four days. Excess stain was removed by placing them in a solution of $50 \%$ glycerol and $0.5 \% \mathrm{KOH}$ for at least a day after which they were stored in $100 \%$ glycerol with a few crystals of thymol to avoid fungal growth. All steps were carried out on a gyrating platform at a low setting.

\section{Zebrafish protocol for optical tomography}

Axolotls of stages 54, 55 and $1.5 \mathrm{~cm}$ were cleared and stained following a protocol developed by Silke Berger from the Currie Laboratory (Australian Regenerative Medicine Institute, Monash University) for Optical Tomography on zebrafish and modified by Catherine Anne Boisvert. The larvae were eviscerated and dehydrated before being bleached in a mixture of formamide, SSC (sodium chloride citrate) and $\mathrm{H}_{2} \mathrm{O}_{2}$ under a light source for 20 to 25 minutes. They were then washed in PBS, dehydrated to $75 \%$ ethanol and stained in Alcian stain solution (EtOH, glacial acetic acid and $0.01 \mathrm{mg} / \mathrm{ml}$ Alcian blue) for 22 hours. The specimens were washed in $80 \% \mathrm{EtOH} / \mathrm{Tris} / \mathrm{MgCl}_{2}$ and rehydrated and washed in $\mathrm{dH}_{2} \mathrm{O}$. They were then stained for 11 to 24 hours in Alizarin stain $(0.1 \mathrm{mg} / \mathrm{ml}$ in $0.5 \% \mathrm{KOH}$ aqueous solution) and washed in PBS. They were then transferred to an increasing series of glycerol in PBS and stored in $100 \%$ glycerol with a few crystals of thymol. All steps were carried out on a gyrating platform at a low setting.

\section{Taylor and VanDyke protocol}

Ambystoma mexicanum specimens of sizes $2.0 \mathrm{~cm}, 2.5 \mathrm{~cm}$, $3.0 \mathrm{~cm}, 3.5 \mathrm{~cm}$ and $4.0 \mathrm{~cm}$ were cleared and stained according to a protocol developed by Taylor and VanDyke [36] and modified by Catherine Anne Boisvert. The sa- lamanders were eviscerated and washed in $80 \% \mathrm{EtOH} /$ Tris/ $\mathrm{MgCl}_{2}$ before being stained in Alcian blue stain $(0.3 \mathrm{mg} / \mathrm{ml}$ Alcian stain in $80 \% \mathrm{EtOH}$ and glacial acetic acid) for three days. They were neutralized in a saturated solution of sodium borate and bleached for one hour and forty minutes in a solution of $0.5 \% \mathrm{KOH}$ and $\mathrm{H}_{2} \mathrm{O}_{2}$. Muscles were removed in a solution of $2.25 \mathrm{mg} / \mathrm{ml}$ trypsin in saturated sodium borate. They were then stained in Alizarin red solution $(0.1 \mathrm{mg} / \mathrm{ml}$ in $0.5 \% \mathrm{KOH}$ aqueous solution) for two to three days, rinsed in $\mathrm{dH}_{2} \mathrm{O}$ and transferred to an increasing series of glycerol in water. They were stored in $100 \%$ glycerol with a few crystals of thymol. All steps were carried out on a gyrating platform at a low setting.

\section{Immunohistochemistry}

\section{Klymkowsky and Hanken protocol}

Neoceratodus larvae from stages 50 and 51 were stained as whole-mounts according to a protocol modified from Klymkowsky and Hanken [37]. The larvae were refixed overnight in Dent's fixative and bleached for 29 hours in Dent's bleach. The specimens were then rehydrated and washed in 'saline cocktail' (PBS, $0.4 \%$ Triton X-100) before being blocked in 'serum cocktail' (PBS, 0.4\% Triton $\mathrm{X}-100,2 \%$ bovine serum albumin (BSA), 5\% dimethylsulfoxide (DMSO)) for one hour. The specimens were then incubated with the primary antibody against skeletal muscle (Hybridoma gene bank 12/101, $3.7 \mathrm{mg} / \mathrm{ml}$ $\mathrm{IgG}_{1}$ ) diluted 1:50 in 'serum cocktail' for five days at room temperature. They were then washed and reblocked in 'serum cocktail' overnight. The larvae were then incubated in the secondary antibody (488 goat antimouse Alexa antibody by Molecular Probes/Invitrogen; $2 \mathrm{mg} / \mathrm{ml}$ ) diluted 1:150 in 'serum cocktail' for two days at room temperature in the dark. They were then washed in 'serum cocktail' and 'saline cocktail' before being dehydrated to $100 \%$ methanol and transferred to an increasing series of BABB (benzyl alcohol/benzyl 
Table 4 Comparison of supinator and pronator muscles in the coelacanth (Latimeria), Australian lungfish (Neoceratodus) and mudpuppy (Necturus)

Latimeria chalumnae Neoceratodus forster

Necturus maculosus

$\begin{array}{ll}\begin{array}{l}\text { Fourth pronator } \\ \text { "4ieme pronateur" }\end{array} & \text { : posterior edge of } \\ \text { the process on the } & \text { fourth axial element } \\ \text { (dorsal) } & \text { Base of the last few } \\ & \text { preaxial lepidotrichia }\end{array}$

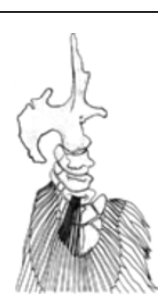

Lepidotrichial O: Lateral sides

flexors (Dorsal))

O: Lateral sides

preaxial lepidotrichia
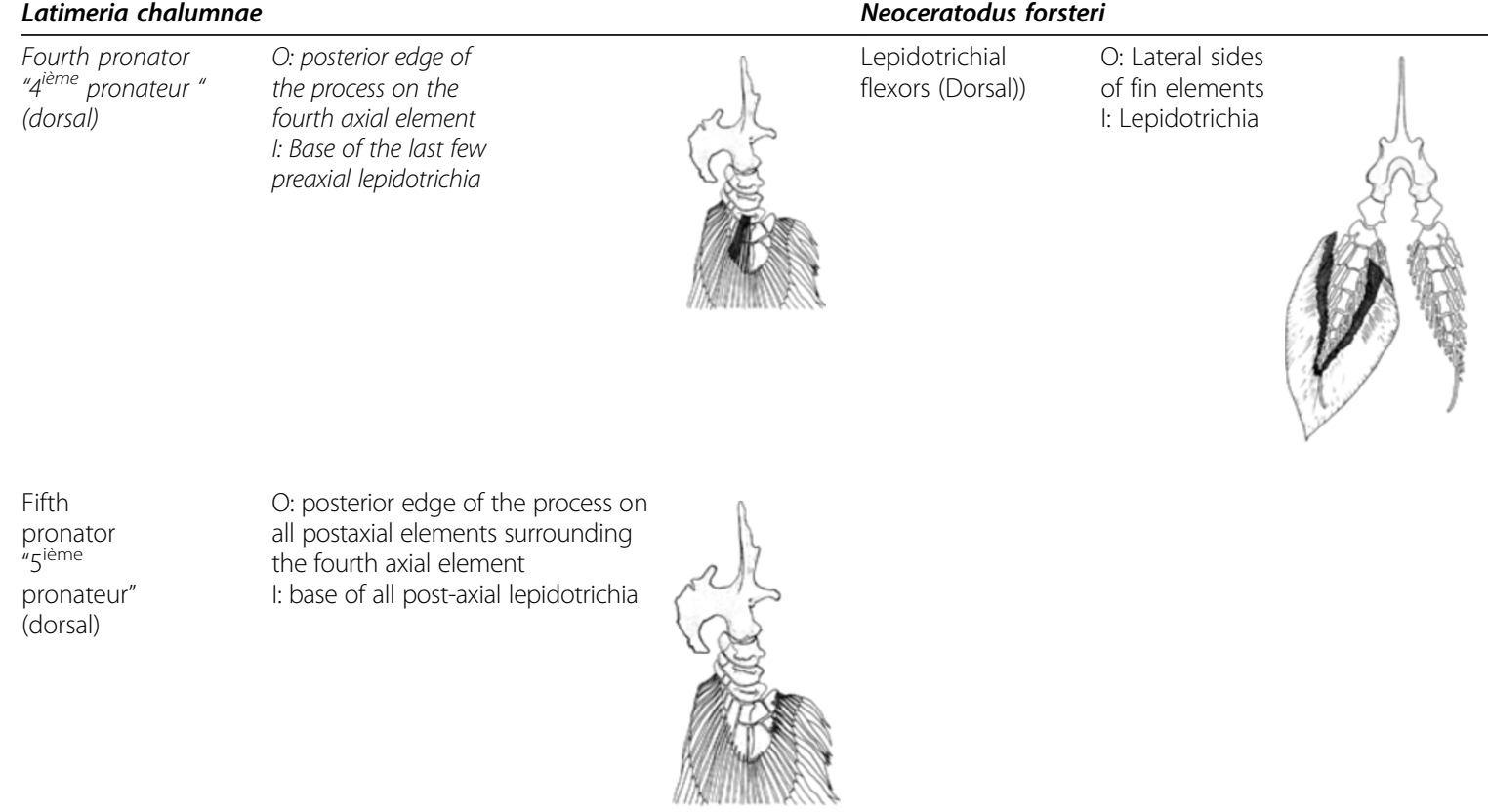

: posterior edge of the process

postaxial elements surrounding he fourth axial element

"5 5 ième

pronateur

\begin{tabular}{ll}
\hline Supinator, second & O:Posterior edge of all four axial \\
layer, group 3. & elements. \\
"Supin couche 2, & I: Preaxial radials and preaxial \\
groupe 3" & lepidotrichia.
\end{tabular}

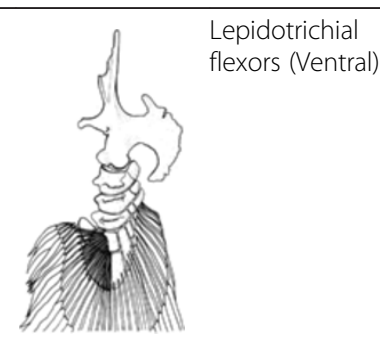

O: Lateral sides

of fin elements

I: Lepidotrichia

groupe 3 "

lepidotrichia.

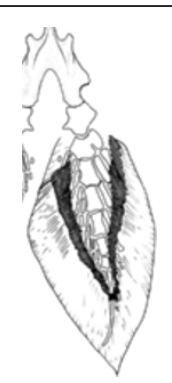

$\begin{array}{ll}\text { Supinator, } & \text { O: Posterior edge } \\ \text { second layer, } & \text { of the fourth } \\ \text { 4th group } & \text { axial element. } \\ \text { "Supin, } & \text { I: Postaxial } \\ \text { couche 2, } & \text { lepidotrichia } \\ \text { groupe 4" } & \end{array}$

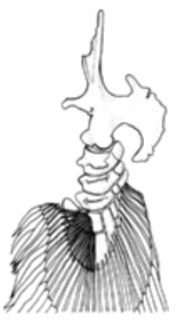


Table 4 Comparison of supinator and pronator muscles in the coelacanth (Latimeria), Australian lungfish (Neoceratodus) and mudpuppy (Necturus) (Continued)

\begin{tabular}{|c|c|c|c|c|}
\hline Latimeria chalumnae & & Neoceratodus forster & & Necturus maculosus \\
\hline $\begin{array}{l}\text { Supinator, second } \\
\text { layer, group } 3 \\
\text { "Supin, couche 2, } \\
\text { groupe 3" }\end{array}$ & $\begin{array}{l}\text { O: Posterior edge of all four } \\
\text { axial elements. } \\
\text { I: Preaxial radials and preaxial } \\
\text { lepidotrichia. }\end{array}$ & $\begin{array}{l}\text { Radial-axial } \\
\text { (Ventral and dorsal ) }\end{array}$ & $\begin{array}{l}\text { O: All axial } \\
\text { elements } \\
\text { । : All radial } \\
\text { elements }\end{array}$ & \\
\hline $\begin{array}{l}\text { Supinator, first layer. } \\
\text { "Supin, couche1" }\end{array}$ & $\begin{array}{l}\text { O: postaxial region between the } \\
\text { base of the mesial hypophysis } \\
\text { (anteriorly) and the arcuate ridge } \\
\text { (posteriorly) } \\
\text { l: through a tendon to the preaxial } \\
\text { radials and preaxial lepidotrichia }\end{array}$ & & & \\
\hline
\end{tabular}

Supinator, second $\quad 0$ : postaxial side of the arcuate ridge layer, group 2 "Supin I: Preaxial radials and preaxial couche 2, groupe 2 " lepidotrichia.

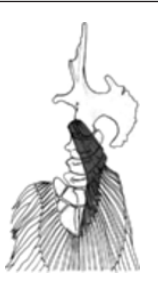

Popliteus (pronator O: Underside of and supinator) the femur near

the femur near puboischiofemoralis externus) 
Table 5 Comparison of hypaxial musculature in the coelacanth (Latimeria), Australian lungfish (Neoceratodus) and mudpuppy (Necturus)

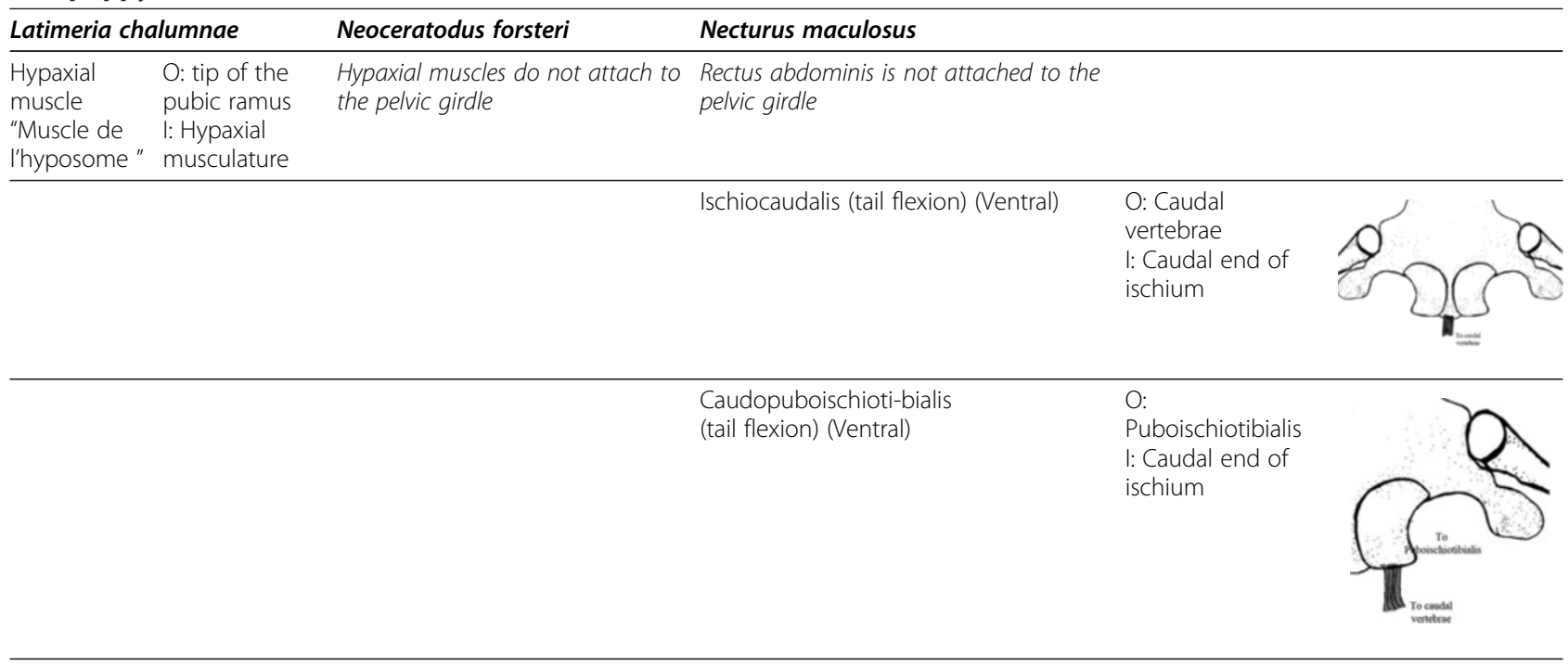

benzoate). All steps were carried out on a gyrating platform at a low setting.

\section{Currie Laboratory protocol}

The remainding stages of Ambystoma and Neoceratodus larvae were immunostained according to a protocol developed by Silke Berger and adapted by CAB. The pelvic region was dissected out, skinned and eviscerated. The specimens were bleached in an aqueous solution of $\mathrm{H}_{2} \mathrm{O}_{2}$, formamide and SSC. Specimens were permeabilized by a trypsin treatment $(0.25 \%$ trypsin in PBST) and acetone cracking. Specimens were then washed in PBST and blocked for six hours in PBS containing 1\% BSA and $1 \%$ DMSO. They were then incubated in the primary antibody against skeletal muscle (Hybridoma gene bank 12/101, $38 \mu \mathrm{g} / \mathrm{ml} \mathrm{IgG}_{1}$ ) diluted 1:10, washed in PBS/BSA/DMSO and incubated in Alexa Fluor 568 goat anti-mouse $\operatorname{IgG}_{1}(\gamma 1) 2 \mathrm{mg} / \mathrm{ml}$ (Molecular Probes/Invitrogen A21124) diluted 1:150 in PBS/BSA/DMSO. They were then washed in PBS/BSA/DMSO, then in PBS over a day before being embedded in $1.5 \%$ low melting point agarose (BDH Electran, VWR $444152 \mathrm{~g}$ ) in PBS. The blocks were left to solidify and dry at $4^{\circ} \mathrm{C}$ in the dark, were trimmed and slowly dehydrated to $100 \%$ methanol before being cleared through an increasing series of $\mathrm{BABB}$. Most steps were carried out on a gyrating platform at a low setting.

\section{Imaging}

All specimens were examined with a Leica MZ FLIII dissecting microscope and photographed using a Leica DFC 490 camera and the Leica Fire cam program. Fluorescent samples were examined with a mercury lamp and Leica GFP filters.

\section{Results}

Development of the pelvic girdle in the Australian lungfish

Kemp's staging table for Neoceratodus [35] stops at stage 55 and no staging table currently exists for older stages. Older larvae have been given a stage starting at number 56 according to general growth. These stage numbers are indicated between single quotation marks to differentiate them from the published staging table [35]. At stage 49 , the pelvic girdle is already present as two narrow bands of cartilage curving mesially but not meeting at the midline (Figure 2A). In the following stages, the pelvic cartilage gradually thickens (Figure 2B). During stages 52 and 53, the pelvis gradually elongates anteriorly and the two halves start fusing at the midline (Figure 2C). During stages 54 and 55, the halves of the pelvic girdle progressively fuse anteriorly at the midline but not between the acetabula. A gap is visible between the acetabula until it closes at stage ' 56 ' and thickens at stage '59' (Figure 2D). At stage '60', the pubic process appears as a small triangular projection much thinner than the rest of the pelvis. At stage '61', the pubic process is much longer and forms the extremity of a large triangle formed by the pelvis itself (Figure 2E and F). At this stage, cartilage anterior to the acetabula is thick and a crescentric arch of strongly chondrified tissue is visible, bridging the left and right sides of the pelvic girdle. This morphology is very similar to that of a larger juvenile as described by Young et al. [15].

\section{Development of the pelvic girdle in the axolotl}

Stage 54 [34] marks the beginning of pelvic development in the axolotl with the appearance of the pubis as a condensation anterior to the future acetabulum (indicated 
as the area between the pubic condensation and the femur) (Figure 2G). An anlage of the femur is also present at this stage posterior to the pubis condensation. (Figure $2 \mathrm{G}_{\text {lateral }}$ ). In the least developed $1.5 \mathrm{~cm}$ larva, the ischium has developed posterior to the pubic cartilage (Figure $2 \mathrm{H}_{\text {ventral }}$ ). The pubis is still only a small condensation of cells at the acetabulum but the ilium is now present (Figure $2 \mathrm{H}_{\text {lateral }}$ ). In another $1.5 \mathrm{~cm}$ larva, the pubis is larger, having extended anteriorly from the acetabulum and towards the midline as a thick condensation. The ischium is also longer, reaching farther posteriorly (Figure $2 \mathrm{I}_{\text {ventral }}$ ). The ilium is longer, projecting postero-dorsally towards the vertebral column (Figure $2 \mathrm{I}_{\text {lateral }}$ ) but not reaching it. In $2.0 \mathrm{~cm}$ larvae, the pubis is much larger and almost complete anteriorly (Figure $2 J_{\text {ventral }}$ ). It is pierced by the obturator foramen on either side but the halves do not meet in the middle. The ischium is also larger but not complete; each half of the pelvic girdle is still triangular in shape, the anterior extremity being widest. At this stage, the ilium is much longer but far from reaching the vertebral column (Figure $\left.2 \mathrm{~J}_{\text {lateral }}\right)$. Cartilage of the pubis, ischium and ilium continue to thicken and grow in $3.0 \mathrm{~cm}$ larvae but there is little change in overall shape. Both sides of the pelvic girdle are still unfused and roughly triangular in shape. The major difference is the development of the sacral rib and the elongation of the ilium towards it (Figure 2K). In the most developed larvae of the series (a $3.5 \mathrm{~cm}$ larva), the ypsiloid cartilage is complete and both sides of the pubis and ischium are almost fused (Figure $\left.1 \mathrm{~L}_{\text {ventral }}\right)$. The ilium almost connects with the sacral rib and has started ossifying (white zone close to its base) but is not calcified yet, preventing the Alizarin red from binding (Figure $1 \mathrm{~L}_{\text {lateral }}$ ).

A schematic comparative representation of pelvic development in Neoceratodus and Ambystoma, aligned using the acetabulum as a fixed landmark, is shown in Figure 3.

\section{Comparison of the pelvic musculature in adult Latimeria, Neoceratodus and Necturus}

Table 1 displays equivalences of pelvic muscles in Latimeria, Neoceratodus and Necturus. Comparison of the musculature of Neoceratodus and Necturus is relatively straightforward and most muscles present in Neoceratodus can be associated with one or several present in Necturus. This is not the case for Latimeria, where text in italics indicates an incomplete equivalence. Often, the point of insertion is much more distal than in Neoceratodus or Necturus and it is often on lepidotrichia rather than endoskeletal fin elements. In some instances this may be the result of an incomplete dissection and it is possible that some of the muscles written in italics actually are equivalent to those of Neoceratodus and
Necturus noted in plain text on the same row. However, these identifications should be regarded as tentative until a re-examination of Latimeria is made. For all tables, the names of the muscles were taken from their original description and have been directly translated from French for Latimeria.

\section{Adductor muscles}

All adductor muscles in Latimeria insert very distally on the fin, making each one an incomplete equivalent to those of Neoceratodus and Necturus. However, equivalences between Neoceratodus and Necturus are easily established. Only two muscles do not have equivalents. The mesial adductor of Neoceratodus was described by Young et al. [15] as linking muscles of both fins from either side. This is unique for Neoceratodus. In Necturus, the puboischiofemoralis externus, a superficial adductor originating from the pubis and ischium and inserting at the base of the femur, cannot be equated with any muscle present in Neoceratodus.

\section{Abductor muscles}

Abductor muscles equivalences are displayed in Table 2. Again, all muscles described in Latimeria insert very distally on the fin, either on lepidotrichia or on muscles inserting onto lepidotrichia. An incomplete equivalence can be established between the pelvic abductor of Latimeria and the iliofibularis of Necturus with no equivalent in Neoceratodus. The iliofemoralis of Necturus originating at the base of the ilium and inserting on the caudal edge of the femur does not have an equivalent in Latimeria or Neoceratodus.

\section{Adductor/Abductor muscles}

Table 3 presents muscles that either have an adductor or abductor function. The radial flexors of Neoceratodus can be equated to the shank flexors and extensors of Necturus.

\section{Supinators and pronators}

Many supinators and pronators have been described for Latimeria and most of them can be equated to lepidotrichial flexors and radial-axials present in Neoceratodus. Lepidotrichial flexors do not have equivalents in $\mathrm{Nec}$ turus since lepidotrichia have been lost during the finlimb transition and are, therefore, absent in all tetrapods. The radial-axials of Neoceratodus and their equivalents in Latimeria cannot be directly equated to muscles in Necturus, lacking pre- and post-axial radials in a 'fish configuration', but given that fish distal radials are precursors to digits $[3,38]$, it is possible that those muscles were the precursors of tetrapod digit musculature. The only supinator muscle in Latimeria that has no equivalent in Neoceratodus is the supinator of the second layer, 


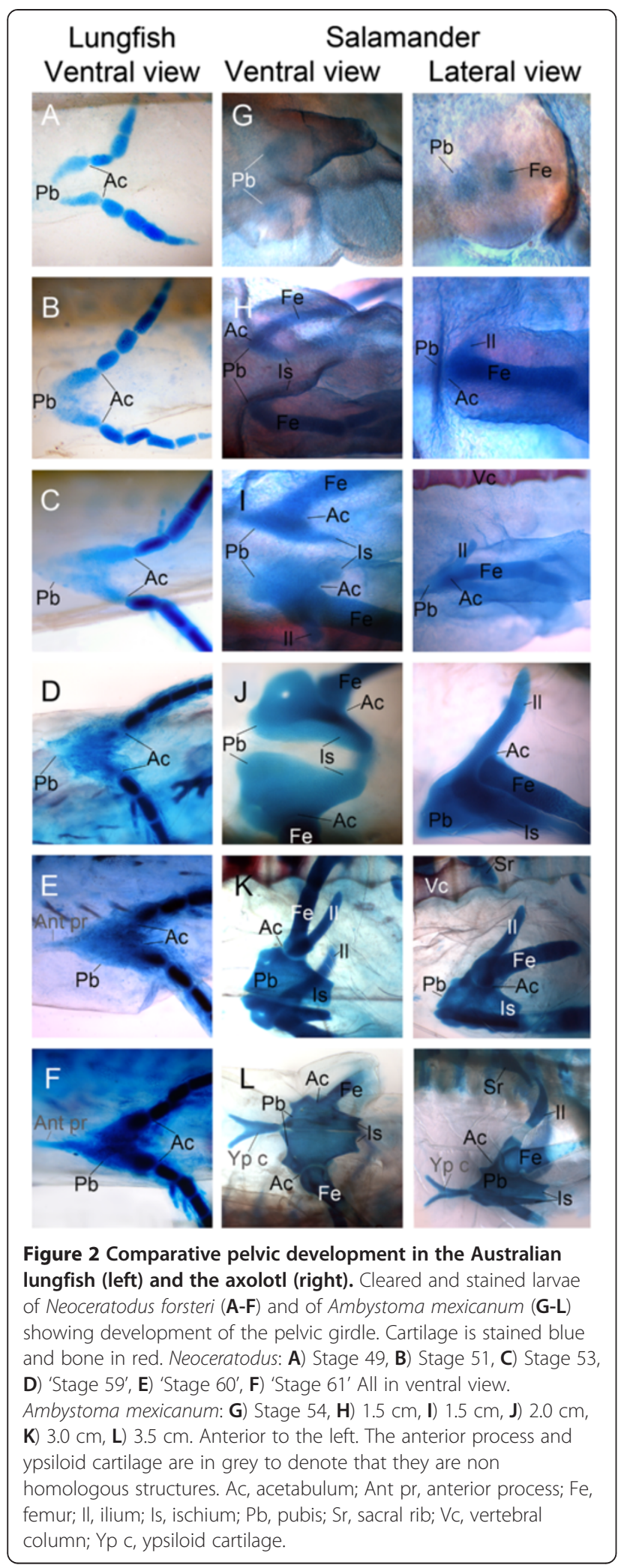

second group which originates from the pelvic girdle and inserts on preaxial radials and preaxial lepidotrichia. The popliteus of Necturus, wrapping around the knee, does not have direct equivalents in Latimeria or Neoceratodus since this muscle is specific to the tetrapod configuration of a knee joint.

\section{Hypaxial musculature}

Table 5 displays hypaxial muscles attaching to the pelvic girdle. No complete equivalences can be established despite the fact that Latimeria, Neoceratodus and Necturus all have a specific pelvic component of the hypaxial musculature. In Latimeria, the hypaxial muscle inserts onto the tip of the pubic ramus but neither the hypaxial musculature in Neoceratodus nor the rectus abdominis insert on the pelvic girdle. Two hypaxial muscles inserting on the ischium are present in Necturus but not in Latimeria and Neoceratodus. These are involved in tail movement and are specific to tetrapods in more or less elaborated ways [39].

\section{Development of the pelvic musculature in the Australian lungfish}

At stage 50, there is no trace of pelvic musculature. Only the hypaxial musculature is visible in lateral and ventral views (Figure 4A). At stage 51, the deep ventral abductor depressor (D. V. abd. depr.), the deep ventral adductor depressor (D. V. add. depr.) and the dorsomesial adductor levator (Dm add. lev.) appear (Figure 4B) as short and thin muscles. These muscles are longer and thicker (Figure 4C) at stage 52 and are accompanied by radial flexors (R.f.) over five or six axial elements and radial-axials (R.-A.) on the pre-axial side of the second element. Radial flexors proximal on the fin are more developed than the ones more distal and these muscles seem to develop in a proximo-distal direction following the development of axial elements. The deep ventral abductor depressor continues to develop anteriorly at stage 54 and the superficial ventrolateral adductor (S. vl. add.) is now present between the dorsal side of the pelvis and the postaxial edge of the fin (Figure 4D). No new muscles appear at stage 56. However, the dorsomesial adductor levator is more developed and its fibers extend more distally. The radial flexors are also longer, and the radial-axials extend on all six axial elements pre-axially and appear for the first time on post-axial radials (Figure 4E). At stage 61, proximal muscles (D. V. abd. depr. and Dm. add. lev.) are fully developed and begin being covered by the superficial ventromesial abductor (S. vm. abd.), which originates at a very anterior position on the pelvic girdle (Figure 4F). Radial-axials on the post-axial side of the fin are now present through its entire length. Lepidotrichial flexors (L.f.) are present through the entire pre-axial side of the fin but are only 


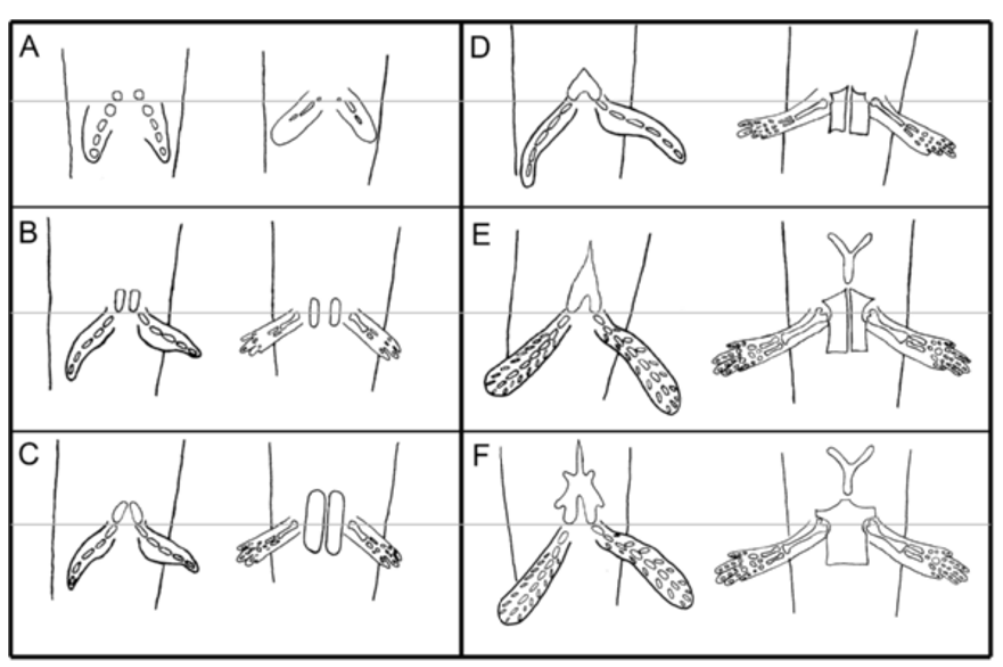

Figure 3 Schematic representation of pelvic development in the Australian lungfish and the axolotl. Each panel compares pelvic development of the Australian lungfish (left side of each panel) and the axolotl (right side). The grey line marks the position of the acetabulum. A) Beginning of pelvic development through cartilaginous condensations at the acetabula. B) The condensations extend anteriorly for the lungfish (pubis) and posteriorly (ischium) and slightly anteriorly (pubis) for the axolotl. C) The pubis of the lungfish continues to extend anteriorly and the pubis of the axolotl grows anteriorly. D) The pubis of the lungfish is now fused at the midline and is triangular shaped. The axolotl pubis is complete anteriorly and the ischium is complete posteriorly. E) Anterior growth of the lungfish pelvic process and appearance of the ypsiloid cartilage in the axolotl. F) Adult morphology of the pelvic girdle in both species. Anterior is at the top.

covering the second and third elements post-axially. By stage 63, all pelvic muscles have appeared except for the mesial adductor (Figure 4G). The superficial ventromesial abductor is more developed and reaches farther anteriorly onto the pelvic girdle. The dorsolateral abductor levator (Dl. Abd. lev.) can be seen as a swelling on the pre-axial side of the fin at the level of the first axial element (Figure $4 G_{1}$ ). The superficial ventrolateral abductor (S. vl. abd.) is now present, visible as thin fibers reaching to the body myotomes (Figure $4 \mathrm{G}_{\mathrm{ld}}$ ) and in ventral view, in the middle of the post-axial muscle bundles (Figure 4G $\mathrm{G}_{\mathrm{v}}$ ). Radial-axials are completely covered by radial flexors and lepidotrichial flexors, now well developed both on the pre and post-axial sides of the fin.

\section{Development of the pelvic musculature in the axolotl}

The very first stage of this series is at the pelvic bud stage 55 [34] when only the rectus abdominis (R. a.) and the caudofemoralis (Cfe) are present, both of which are extensions of the hypaxial musculature (Figure 5A). Those muscles flank the emerging limb bud and at the following stage $(1.5 \mathrm{~cm})$, the ischiofemoralis (Isfe), the puboischiofemoralis internus (Pisfe int) and the iliofemoralis are all present (Figure $5 \mathrm{~B}_{1}$ ) (all muscles inserting into the limb). At $2.0 \mathrm{~cm}$, the caudofemoralis muscle now extends all the way to the base of the femur and is a lot thicker. The puboischiotibialis (Pist) is now covering the ischiofemoralis and the caudopuboischiotibialis
(Cpist) is now visible, linking the puboischiotibialis to bands of muscles extending towards the caudal vertebrae (Figure $5 \mathrm{C}_{1}$ ). Fibers of the iliofemoralis now extend caudally, suggesting that its point of origin on the ilium extends dorsally in connection with the dorsal extension of the iliac cartilage (Figure 2). Shank flexors (Figure $5 \mathrm{C}_{\mathrm{l}}$ ) and extensors (Figure $5 \mathrm{C}_{\mathrm{v}}$ ) are now present, as well as the pubotibialis (pt), visible in the middle of the thigh in the ventral view. The $2.5 \mathrm{~cm}$ larva is very similar to the previous stage except for the distal leg muscles, which are missing along with the rest of the leg in this individual, having fallen victim to cannibalism (a common behavior in axolotl). The puboischiotibialis is thicker and extends farther anteriorly, the iliofemoralis extends a little more dorsally and the caudopuboischiotibialis can be clearly seen connecting the puboischiotibialis to muscle fibers extending to the caudal vertebrae (Figure $5 D_{1}$ ). In the ventral view, the puboischiofemoralis externus (Pisfe ext) is now present, its origin overlapping with that of the puboischiofemoralis internus (Figure $5 D_{v}$ ). Due to species variation in the pelvic shape, fibers of the puboischiofemoralis externus are more parallel to the hypaxial musculature than those of Necturus but can be distinguished from it by its posterior point of origin. The ischioflexorius (Isfl) is probably present at this stage as a very faint band of muscle originating from the ischium and extending distally on the post-axial side of the thigh (Figure $5 \mathrm{D}_{\mathrm{vd}}$ ). The last stage of this series is very similar to $2.5 \mathrm{~cm}$. At $3.0 \mathrm{~cm}$, the ischioflexorius is thicker and more visible and shank extensors and flexors as well as the 
popliteus are present (Figure $5 \mathrm{E}_{\mathrm{d}}$ ). All other muscles seem to have reached their adult conformation (Figure 5E) but the ischiocaudalis, the iliotibialis, ilioextensorius and iliofibularis cannot be seen in any view. They are all small, deep muscles, which may be covered by more superficial muscles, or they might be absent altogether in Ambystoma.

\section{Discussion}

\section{Comparative pelvic development and hypotheses of}

\section{pelvic evolution}

One of the major questions about the evolution of the tetrapod pelvic girdle during the fish-tetrapod transition has been the apparent shift in position of the acetabulum. In sarcopterygian fish, the fin articulation is located posteriorly on the pelvic girdle $[11,12,15]$ whereas in early tetrapods, it is lateral [16,17] (Figure 1). This seems to imply that the acetabulum has moved across the lateral face of the pelvis during the transition. However, the fact that the acetabular region is the first part of the pelvis to develop in both Neoceratodus and Ambystoma suggests that the acetabulum should instead be regarded as a fixed landmark (grey line, Figure 3). Such a change of perspective makes the evolutionary transformation of the pelvis much easier to understand. As shown in the descriptions above, the principal difference in early pelvic development between salamander and lungfish is that in the salamander, the pubis grows anteriorly and the ischium posteriorly from the acetabular region, whereas in lungfish the pubis grows anteriorly and the ischium is absent; in other words, chondrogenic cells proliferate both anteriorly and posteriorly in the salamander, whereas in the lungfish they only proliferate anteriorly. The presence of an ischium and the lateral position (and orientation) of the acetabulum are,

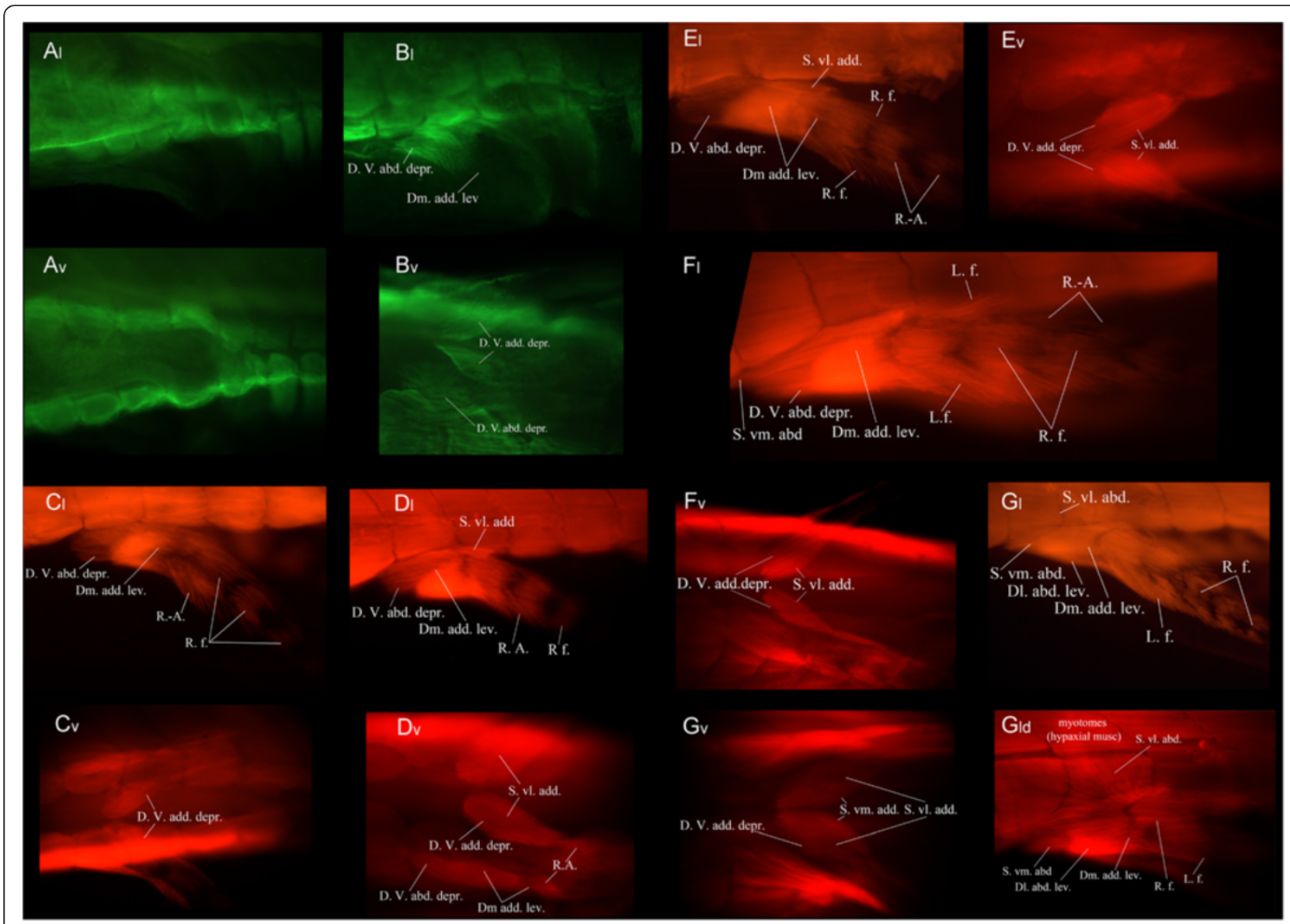

Figure 4 Pelvic musculature development in the Australian lungfish. Immunostained larvae of Neoceratodus forsteri showing the developing pelvic musculature. All stages were incubated in a primary antibody against skeletal muscle. $\mathbf{A}$ and $\mathbf{B}$ were visualized through a secondary anti-mouse 488 Alexa antibody and $\mathbf{C}$ and $\mathbf{D}$ were visualized with a secondary anti- $\lg \mathrm{G}_{1}(\gamma 1) 568$ Alexa antibody. v: ventral view and l: lateral view. A) Stage 50, B) Stage 51, C) Stage 52, D) Stage 54, E) Stage '56', F) Stage '61', G) Stage '63'. DI. Abd. lev., dorsolateral abductor levator; Dm. add. lev., dorsomesial adductor levator; D. V. abd. depr., deep ventral abductor depressor; D. V. add. depr., deep ventral adductor depressor; L.f., Lepidotrichia flexors; R.-A., radial-axials; R. f., radial flexors; S. vl. abd., superficial ventrolateral abductor; S. vl. add., superficial ventrolateral adductor; S. vm. abd., superficial ventromesial abductor. Anterior to the left. 
therefore, developmentally coupled morphological states, presumably resulting from a change in molecular signalling in the immediate ancestors to tetrapods: there is no need to postulate a 'migration' of the acetabulum. Figure 3 schematizes pelvic development in lungfish and axolotl with this hypothesis in mind. The grey line represents the position of the acetabula for both species.

Another major question about the evolution of the pelvic girdle in tetrapods concerns the origin of the ilium and its relationship, if any, to the presence of an iliac process in Eusthenopteron, Goologongia and other fish members of the tetrapod stem group $[11,12,14,15]$. The fact that the ilium of salamanders slowly extends dorsally during development, only contacting the sacral rib at a late stage when the pelvis is more or less fully formed, means that the ilium passes through a protracted developmental stage when it closely resembles the iliac process of these fishes (Figure 1). Together with the wide phylogenetic distribution of the iliac process, which suggests that it is a general character for the 'fish' part of the tetrapod stem group $[11,12,14,15]$, this provides strong circumstantial evidence for the homology of the two structures.

\section{Muscle homologies in Coelacanth, Lungfish and a salamander, and the evolution of pelvic musculature}

Here, the muscles of Necturus are described as a model for basal salamanders. There are almost twice as many muscles originating from the pelvic girdle in salamanders as in lungfish (13 versus 7) but six of these muscles are either originating or inserting on the ischium, which is a purported novelty in tetrapods. Very few pelvic muscles present in Necturus could not be associated with a muscle present in Neoceratodus. Among the exceptions is the puboischiofemoralis externus, originating mostly on the anterior process of the pubis, which is probably not homologous to the pubic process of Neoceratodus. However, the puboischiofemoralis is the only muscle with an ischiatic origin that could not be compared to a muscle in Neoceratodus. In all other cases, muscles originating from the mesial surface of the pelvic girdle in Neoceratodus had the same function and were very similar in terms of insertion point to muscles originating from the ischium in Necturus. This suggests that the ischium originated as an inflation of the posteromesial face of the pubis, created by increased proliferation of chondrogenic cells posterior to the acetabulum, an interpretation that also fits well with the data from skeletal development (Figures 2, 3). If the ischium is, in fact, a posterior projection of the pubis, the muscle groups paired up in Tables 1, 2, 3, 4 and 5 are likely to be truly homologous and the muscles themselves would not have changed substantially during the fish-tetrapod transition. This is consonant with the results from the comparative study of muscle development (see below). As for muscles originating from the ilium in Necturus, almost all seem to correspond to muscles originating from the posterodorsal surface of the pelvic girdle in Neoceratodus. Most known pelvic girdles of fossil tetrapodomorph fish have a lateral ridge or process on their posterodorsal surface $[11,12,14,15]$. Most of these ridges are very slight but given the fact that muscles originating on the ilium in Necturus originate at the very base of it, a homologous muscle could in principle originate from a small process situated at the same position on the pelvic girdle of a fish. This gives further support to the hypothesis that the iliac process of Eusthenopteron and other fish members of the tetrapod stem group is the precursor to the ilium of tetrapods.

\section{Comparative muscular development}

In both Ambystoma and Neoceratodus, the hypaxial musculature develops first, followed by deep musculature originating from the pelvic girdle and inserting proximally onto the fin/limb. All muscles that have been equated in the tables above develop in the same order except for the caudofemoralis, which is the first pelvic muscle to develop in axolotls. Its homologue, the superficial ventrolateral abductor, develops last. This suggests a large heterochronic shift in the appearance of this muscle. The other, less dramatic, exception is the ischioflexorius, which develops slightly earlier in sequence than its counterpart, the superficial ventromesial adductor. The deep ventral abductor depressor, equivalent to the puboischiofemoralis internus, and the deep ventral adductor depressor, equivalent to the ischiofemoralis is the first homologous pair to appear. The dorsomesial adductor levator then appears in Neoceratodus and the iliofemoralis, in Ambystoma. These muscles have not been homologized on the basis of origin and insertion points but their developmental sequence might indicate some homology. The dorsomesial adductor levator of lungfish develops in the same sequence as the iliofemoralis and the radial-axial develop simultaneously to the caudopuboischiotibialis. Homologous pairs of slightly more superficial muscles appear next: the radial flexors/ shank flexors and the superficial ventrolateral adductor/ puboischiotibialis. The first of the superficial muscles to form in Ambystoma is the puboischiofemoralis externus, which was not homologized to any muscle in lungfish and is followed by the ischioflexorius. Its homologue (superficial ventromesial adductor) develops slightly later in lungfish, after the appearance of the superficial ventromesial abductor (synchronous with the development of the pubotibialis). This heterochronic shift might be functional in nature or an artefact of the whole mount staining method where discerning incompletely differentiated muscles can be difficult. Lepidotrichal flexors and 


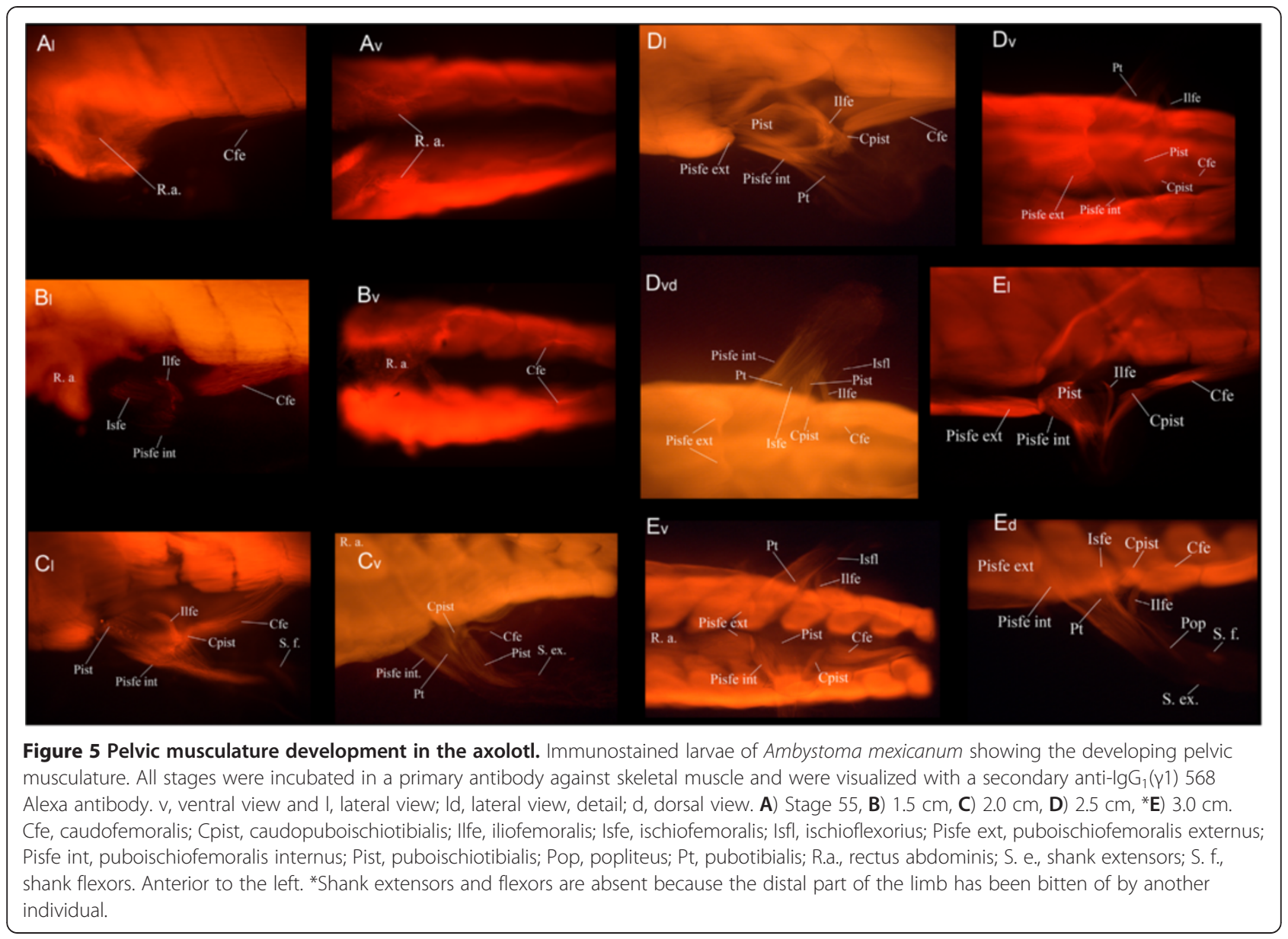

the popliteus develop last. This might be due to the superficial nature of those muscles. Despite large differences in pelvic morphology, development of both the cartilage and muscles of these species is thus very similar. One important difference is that while the order of appearance is the same, there is more lag between consecutive muscle appearances in Neoceratodus. While several muscles appear at once in Ambystoma, new muscles appear one by one in Neoceratodus.

Further insight can be gained from the direction in which muscles develop. For example, the iliofemoralis is one of the first pelvic muscles to appear in $1.5 \mathrm{~cm}$ long Ambystoma larvae, the stage at which the ilium starts to extend dorsally (Figure $\left.2 \mathrm{I}_{\text {lateral }}\right)$. This muscle continues to extend dorsally, presumably following the ilium. The same thing is true for muscles attaching to the pubis: in both Neoceratodus and Ambystoma, muscles originating from the pubis extend anteriorly through development, presumably following the anterior extension of the pubic cartilage. Similarly, radial-axial and lepidotrichial flexors of the fins of Neoceratodus start to develop pre-axially before developing post-axially, in a manner resembling that of the appearance of radials on the fin [38]. In summary, the sequence and mode of development of the pelvic musculature appears to be substantially conserved between Neoceratodus and Ambystoma, suggesting that the morphological transformation from pelvic fin to tetrapod hind limb was accomplished without major heterochronic reorganization of muscle development.

\section{Conclusions}

Despite large differences in pelvic morphology, the development of the pelvic girdle in Neoceratodus and Ambystoma is strikingly similar. Most pelvic muscles can be homologized between the two species and homologous muscles develop in the same order. Deep muscles develop first, followed by some muscles unique to either lungfish or salamanders and superficial muscles develop last. The only exception to this gradual development from deep to superficial is the appearance of the caudofemoralis of the axolotl at the very beginning of development whereas the superficial ventrolateral abductor of the lungfish develops last, along with the rest of the superficial musculature. The caudofemoralis 
originates from caudal vertebrae and is involved in tail motion. Its early appearance might be due to the very large reliance on undulatory motion of larval axolotls. Its early development might also be a consequence of the derived mode of development recently described for tetrapod pelvic appendages [40]. In lungfish, pelvic fin musculature develops from both a myotomal extension from the body wall and the migration of somite derived mesenchymal cells. However, in tetrapods, including Ambystoma, pelvic limb muscle formation is solely dependent on somite derived mesenchymal cells; it is argued that this mode of development would allow for earlier initiation and easier heterochronic reorganization of muscle development.

With regards to the skeleton, if we consider the acetabulum to be a fixed landmark, the evolution of the ischium simply required pre-chondrogenic cells of the pubis to migrate posteriorly as well as anteriorly in order to form it. This would explain why very similar muscles originating from the inside of the pubis in the lungfish originate from the ischium in the salamander. The ischium does not ossify in neotenic forms, such as the axolotl. However, in several salamander taxa, the ischium ossifies whilst the pubis remains unossified (Personal observation, $C A B$ ). This is reminiscent of the condition in early tetrapods [2] and might have initially been caused by the greater reliance on muscles originating from the ischium such as the puboischiotibialis. Ossification would have occurred in the ischium as a result of muscular tension which is known to promote ossification $[41,42]$. It would be interesting to combine the results of this study and recent biomechanical studies $[8,43]$ to test those hypotheses. As for the origin of the ilium, some very similar muscles originating from the posterodorsal surface of the pelvis in Neoceratodus originate from the base of the ilium in Ambystoma, suggesting that the lateral ridge or process present in most tetrapodomorph fish is the precursor of the tetrapod ilium (Figure 1). This precursor would then have extended dorsally to eventually reach and articulate with the sacral rib, as observed by the development of both iliac cartilage and muscles. In order to test those hypotheses, the origin and insertion points of the muscles of Latimeria, Neoceratodus and Ambystoma should be verified using three-dimensional models generated from undissected computed tomography (CT)-scanned specimens. This will provide a more robust comparative morphological framework against which to analyze triple-stained (double immunostained for muscles and nerves plus alcian stained for cartilage) growth series of Neoceratodus and Ambystoma by optical tomography (OPT), which allows for three-dimensional three-color visualization. As a complement to these techniques for investigatng extant morphologies, the application of propagation phase contrast synchrotron microtomography (PPC-SR $\mu \mathrm{CT})$ to the study of fossil bone histology is opening up new possibilities for detecting muscle attachments on the pelvic bones of fossil fishes and early tetrapods [44]. We expect that data extracted by these novel methods will cast a great deal of light on the transformation of the pelvic appendage at the fish-tetrapod transition and perhaps help resolve the question of the origin of tetrapod locomotion raised in several recent publications $[8,43,45]$.

\section{Abbreviations \\ Lungfish and Axolotl pelvic girdle \\ Ac: Acetabulum; Ant pr: Anterior process; Fe: femur; Il: ilium; Is: ischium; Pb: pubis; Sr: Sacral rib; Vc: Vertebral column; Yp c: ypsiloid cartilage; \\ Lungfish pelvic musculature}

DI. Abd. lev: dorsolateral abductor levator; Dm. add. lev: dorsomesial adductor levator; D. V. abd. depr: deep ventral abductor depressor; D. V. add. depr: deep ventral adductor depressor; L.f: lepidotrichia flexors; S vl abd: Superficial ventrolateral abductor; S vl add: superficial ventrolateral adductor; S. vm. abd: superficial ventromesial abductor; R.-A: radial-axials; R. f: Radial flexors;

\section{Axolotl pelvic musculature}

Cfe: caudofemoralis; Cpist: caudopuboischiotibialis; Ilfe: iliofemoralis; Isfe: ischiofemoralis; Isfl: ischioflexorius; Pisfe ext: Puboischiofemoralis externus; Pisfe int: Puboischiofemoralis internus; Pist: Puboischiotibialis; Pop: Popliteus; Pt: Pubotibialis; R.a: Rectus abdominis; S. e: Shank extensors; S. f: Shank flexors.

\section{Competing interests}

The authors declare that they have no competing interests.

\section{Authors' contributions}

CAB planned and performed the experiments, collected the data, prepared the manuscript and the figures. PEA contributed to the conception and design of the experiments and to the analysis and interpretation of the data. JMPJ contributed materials and all authors contributed, read and approved the final manuscript.

\section{Acknowledgements}

We would like to thank Rolf Ericsson and Elizabeth Eyre for the collection and care of egg and larvae of Neoceratodus. CAB would like to thank Laura Muzinic of the Ambystoma genetic stock center for raising and shipping a large quantity of older larvae of Ambystoma. She would also like to thank Silke Berger, Peter Currie and Rob Bryson-Richardson for providing protocol and technical advice. CAB would like to thank Daniel Snitting for proofreading this manuscript. We thank Rui Boliqueime Martins Diogo and two anonymous reviewers for constructive comments on the manuscript. CAB is currently supported by a Human Frontiers Science Program CrossDisciplinary Fellowship (LT000130/2009 L) and two Australian Research Council Discovery Project Grants (DP1096002 and DP110101127). Part of this work was carried out while CAB was a PhD student at Uppsala University; at that time, she was supported by Uppsala University and the Swedish Research Council, through a grant to PEA. At present, PEA is supported by a Wallenberg Scholarship provided by the Knut and Alice Wallenberg Foundation. JMPJ is supported by the Australian Research Council. The monoclonal antibody 12/101 developed by Jeremy P. Brockes was obtained from the Developmental Studies Hybridoma Bank developed under the auspices of the NICHD and maintained by The University of lowa, Department of Biological Sciences, lowa City, IA 52242, USA.

\section{Author details}

${ }^{1}$ Australian Regenerative Medicine Institute, Monash University, Wellington Road, Clayton, VIC 3800, Australia. '2Subdepartment of Evolution and Development, Department of Organismal Biology, Evolutionary Biology Centre, Uppsala University, Norbyvägen 18A, Uppsala 752 36, Sweden. 
${ }^{3}$ School of Biological Sciences, Macquarie University, Sydney, NSW 2010, Australia.

Received: 14 September 2012 Accepted: 3 December 2012 Published: 23 January 2013

\section{References}

1. Niedzwiedzki G, Szrek P, Narkiewicz K, Narkiewicz M, Ahlberg PE: Tetrapod trackways from the early Middle Devonian period of Poland. Nature 2010 463:43-48.

2. Clack JA: Gaining Ground: the Origin and Evolution of Tetrapods. 2nd edition. Bloomington, IN: Indiana University Press; 2012.

3. Boisvert CA, Mark-Kurik E, Ahlberg PE: The pectoral fin of Panderichthys and the origin of digits. Nature 2008, 456:636-638.

4. Coates Ml, Ruta M, Friedman M: Ever since Owen: changing perspectives on the early evolution of tetrapods. Annu Rev Ecol Evol Syst 2008, 39:571-592.

5. Clack JA: The fin to limb transition: new data, interpretations, and hypotheses from paleontology and developmental biology. Annu Rev Earth Planet Sci 2009, 37:163-179.

6. Brazeau MD, Ahlberg PE: Tetrapod-like middle ear architecture in a Devonian fish. Nature 2006, 439:318-321.

7. Daeschler EB, Shubin NH, Jenkins FAJ: A Devonian tetrapod-like fish and the evolution of the tetrapod body plan. Nature 2006, 440:757-763.

8. Pierce SE, Clack JA, Hutchinson JR: Three-dimensional limb joint mobility in the early tetrapod Ichthyostega. Nature 2012, 486:523-526.

9. Ahlberg PE, Clack JA, Blom H: The axial skeleton of the Devonian tetrapod Ichthyostega. Nature 2005, 437:137-140.

10. Coates MI, Jeffery JE, Ruta M: Fins to limbs: what the fossils say. Evol Dev 2002, 4:390-401.

11. Ahlberg PE: Paired fin skeletons and the relationships of the fossil group Porolepiformes (Osteichthyes: Sarcopterygii). Zool J Linnean Soc 1989, 96:119-166.

12. Andrews SM, Westoll TS: The postcranial skeleton of Eusthenopteron foordi Whiteaves. Transactions of the Royal Society of Edinburgh 1970, 68:207-328.

13. Andrews MS, Westoll ST: The postcranial skeleton of rhipidistian fishes excluding Eusthenopteron. Transactions of the Royal Society of Edinburgh 1970, 68:56-489

14. Johanson Z, Ahlberg PE: Devonian rhizodontids and tristichopterids (Sarcopterygii; Tetrapodomorpha) from East Gondwana. Transactions of the Royal Society of Edinburgh: Earth Sciences 2001, 92:43-74.

15. Young GC, Barwick RE, Campbell KSW: Pelvic girdles of lungfishes (Dipnoi). In Pathways in Geology: Essays in Honour of Edwin Sherbon Hills. Edited by LeMaitre RW. Melbourne: Blackwell Scientific; 1989:59-75.

16. Coates MI: The Devonian tetrapod Acanthostega gunnari Jarvik: postcranial anatomy, basal tetrapod interrelationships and patterns of skeletal evolution. Transactions of the Royal Society of Edinburgh: Earth Sciences 1996, 87:363-421.

17. Jarvik E: The Devonian tetrapod Ichthyostega. Fossils and Strata 1996, 40:1-213.

18. Boisvert CA: The pelvic fin and girdle of Panderichthys and the origin of tetrapod locomotion. Nature 2005, 438:1145-1147.

19. Witmer $L M$ : The extant phylogenetic bracket and the importance of reconstructing soft tissues in fossils. In Functional Morphology in Vertebrate Paleontology. Edited by Thomason JJ. Cambridge: Cambridge University Press; 1995:19-33.

20. McNamara K, McKinney ML: Heterochrony, disparity, and macroevolution. Paleobiology 2005, 31:17-26.

21. Weisbecker V: Monotreme ossification sequences and the riddle of mammalian skeletal development. Evolution 2011, 65:1323-1335.

22. Romer AS, Parsons TS: The Vertebrate Body. 6th edition. Philadelphia: Saunders College Publishing; 1986.

23. Humphry GM: The muscles and nerves of the Cryptobranchus japonicus. J Anat Physiol 1871, 6:1-61. 64 plates.

24. Francis ETB: The Anatomy of the Salamander. Oxford: Oxford University Press; 1934.

25. Appleton $A B$ : The muscles and nerves of the post-axial region of the tetrapod thigh Part I. J Anat 1928, 62:364-400.

26. Winterbottom R: A descriptive synonymy of the striated muscles of the teleostei. Proc Acad Nat Sci Philadelphia 1974, 125:225-317.
27. Abdala V, Diogo R: Comparative anatomy, homologies and evolution of the pectoral and forelimb musculature of tetrapods with special attention to extant limbed amphibians and reptiles. J Anat 2010, 217:536-573.

28. Diogo R, Linde-Medina M, Abdala V, Ashley-Ross MA: New, puzzling insights from comparative myological studies on the old and unsolved forelimb/ hindlimb enigma. Biol Rev 2012. doi:10.1111/j.1469-185X.2012.00247.x.

29. Millot J, Anthony J, Tome I: Squelette, muscles et formations de soutien: Anatomie de Latimera chalumnae. Paris: Centre National de recherces scientifiques; 1958

30. Walthall JC, Ashley-Ross MA: Postcranial myology of the California newt, Taricha torosa. Anat Rec A Discov Mol Cell Evol Biol 2006, 288A:46-57.

31. Walker WF, Homberger DG: Vertebrate Dissection. 8th edition. Orlando: Saunders College Publishing; 1992.

32. Wiens JJ, Bonett RM, Chippindale PT: Ontogeny discombobulates phylogeny: paedomorphosis and higher-level salamander relationships. Syst Biol 2005, 54:91-110.

33. Boisvert CA: Vertebral development of modern salamanders provides insights into a unique event of their evolutionary history. $J$ Exp Zool $B$ 2009, 312:1-29.

34. Nye HLD, Cameron JA, Chernoff EAG, Stocum DL: Extending the table of stages of normal development of the axolotl: limb development. Dev Dyn 2003, 226:555-560.

35. Kemp A: The embryological development of the Queensland lungfish, Neoceratodus forsteri (Krefft). Mem Queensl Mus 1982, 20:553-597.

36. Taylor WR, Van Dyke GC: Revised procedures for staining and clearing small fishes and other vertebrates for bone and cartilage study. Cybium 1985, 9:107-119.

37. Klymkowsky MW, Hanken J: Whole-mount staining of Xenopus and other vertebrates. Methods Cell Biol 1991, 36:419-441.

38. Johanson Z, Joss JMP, Boisvert CA, Ericsson R, Sutija M, Ahlberg PE: Fish fingers: digit homologues in sarcopterygian fish fins. J Exp Zool B 2007, 308B:757-768.

39. Haines RW: Some muscular changes in the tail and thigh of reptiles and mammals. J Morphol 1935, 58:355-383.

40. Cole NJ, Hall TE, Don EK, Berger S, Boisvert CA, Neyt C, Ericsson R, Joss J, Gurevich DB, Currie PD: Development and evolution of the muscles of the pelvic fin. PLoS Biol 2011, 9:e1001168.

41. Hall BK: The role of movement and tissue interactions in the development and growth of bone and secondary cartilage in the clavicle of the embryonic chick. J Embryol Exp Morphol 1986, 93:133-152.

42. Newman SA, Müller GB: Origination and innovation in the vertebrate limb skeleton: an epigenetic perspective. J Exp Zool B 2005, 304B:593-609.

43. King HM, Shubin NH, Coates Ml, Hale ME: Behavioral evidence for the evolution of walking and bounding before terrestriality in sarcopterygian fishes. Proc Natl Acad Sci U S A 2011, 108:21146-21151.

44. Sanchez S, Ahlberg PE, Trinajstic KM, Mirone A, Tafforeau P: Three dimensional synchrotron virtual paleohistology: a new insight into the world of fossil bone microstructures. Microsc Microanal, in press.

45. King HM, Hale ME: Pelvic limb morphology in the lungfish Protopterus annectens. Society for Integrative and Comparative Biology 2012, 1:97.

46. Johanson Z, Ahlberg PE: A complete primitive rhizodont from Australia. Nature 1998, 394:569-573.

47. Kuijper S, Beverdam A, Kroon C, Brouwer A, Candille S, Barsh G, Meijlink F: Genetics of shoulder girdle formation: roles of Tbx15 and aristaless-like genes. Development 2005, 132:1601-1610.

doi:10.1186/2041-9139-4-3

Cite this article as: Boisvert et al:: Comparative pelvic development of the axolotl (Ambystoma mexicanum) and the Australian lungfish (Neoceratodus forsteri): conservation and innovation across the fishtetrapod transition. EvoDevo 2013 4:3. 